\title{
Referencias al Monasterio del Escorial en la transformación urbana de Madrid. La estética del poder en el siglo $\mathrm{XX}$
}

\author{
FRANCISCO DANIEL HERNÁNDEZ MATEO \\ Profesor Titular de Historia del Arte / Universidad Carlos III de Madrid \\ fhernand@hum.uc3m.es
}

\begin{abstract}
Resumen
En Madrid, como en todas partes en Europa, los arquitectos querían una nueva arquitectura, pero suscribir los principios de los Congresos Internacionales de Arquitectura Moderna no bastaba y en Madrid, como en la mayoría de capitales europeas, el modernismo no fue siempre sinónimo de racionalismo. Desde el principio ha habido arquitectos que han denunciado las "disfunciones del funcionalismo", que estaban interesados en soluciones que utilizaban la modernidad, pero nunca en negar su identidad nacional, sino que eran críticos hacia el racionalismo de la Europa central y de la tradición arquitectónica española.

La revista Arquitectura y las enseñanzas de José Ortega y Gasset afirmaban que el barroco era el estilo de arquitectura más genuinamente español y promovieron su recuperación, creando un paralelismo entre el dinamismo barroco y la arquitectura dinámica, como mostraría el futurismo italiano. En 1920 un número especial de la revista Arquitectura se dedicó a ese tema, así como otro número tres años más tarde, sugiriendo que la esencia del barroco fue plasmada en el Monasterio del Escorial, y que debe ser el modelo y la inspiración de la Nueva Arquitectura española. Secundino Zuazo sería el encargado de poner en práctica esta teoría, cuando Indalecio Prieto le pidió que construyera los Nuevos Ministerios, la sede del nuevo gobierno de la Segunda República. Después de la guerra, el cubismo, un arte considerado cercano a los soviets fue prohibido, junto con el libre racionalismo civil, al considerar las autoridades que esas tendencias buscaron "convertir las nobles perspectivas de España en los campos de la alucinación." La arquitectura se había convertido en propaganda política, y el nuevo régi-
\end{abstract}


men necesitaba una nueva arquitectura. Sánchez Mazas, un hombre relacionado con el neoclasicismo y la Ilustración española, fue el que estableció el Monasterio de El Escorial, una vez más, como un modelo. El Ministerio de Aviación se diseñó a su imagen y adaptado a las necesidades de la época del gobierno: el Ministerio del Aire.

Palabras clave: Nueva Arquitectura; Monasterio de El Escorial; arquitectura como propaganda; Nuevos Ministerios; Secundino Zuazo; arquitectura e identidad nacional.

\begin{abstract}
In Madrid, as everywhere else in Europe, architects wanted new architecture; but to subscribe the principles of the International Congresses of Modern Architecture did not suffice; in Madrid, as in most European capitals, modernism was not always synonym of rationalism. From the outset there were architects who denounced the "dysfunctions of functionalism"; they were interested in solutions that used modernity but never denying their national identity; they were both critical towards the rationalism of central Europe, and assertive of the Spanish building tradition.

The magazine Arquitectura and the teachings of José Ortega y Gasset will claim baroque be the more genuinely Spanish architectural style and will promote its recovery; they will set a parallel between Baroque dynamis and the dynamic -and vague- architecture as shown by Italian Futurism. In 1920 a special issue of Arquitectura magazine was devoted to that topic; three years later another one followed, suggesting that the essence of the Baroque was embodied in the Escorial Monastery, and that it should be the model and inspiration of the new Spanish architecture. Secundino Zuazo would be the one to put this theory into practice, as Indalecio Prieto asked him to build the Nuevos Ministerios, the headquarters of the new government of the Second Republic. After the civil war cubism -an art form considered close to the soviets- was forbidden together with free rationalism; authorities considered that those trends sought "to turn the noble perspectives of Spain into fields of hallucination." Architecture had become political propaganda, and the new regime needed a new architecture. Sánchez Mazas, a man related to Spanish neoclassicism and Enlightenment, was the one who set the Escorial Monastery, once again, as a model. The Aviation Ministry was shaped at its image, adapted to the needs of the government period: the Air Ministry.
\end{abstract}

Key words: Escorial Monastery, architecture, political propaganda, Nuevos Ministerios, Secundino Zuazo, dysfunctions of functionalism.

Sumario: 1.- Por una vanguardia cultural y arquitectónica sin renunciar a la identidad española. 2.- España Republicana y Herreriana. 3.- Una 'Nueva Arquitectura' para un 'Nuevo Régimen'. 4.- Referencias bibliográficas. 


\section{Por una vanguardia cultural y arquitectónica sin renunciar a la identidad española.}

Uno de los mejores análisis de la encrucijada que vive la arquitectura española de las primeras décadas del siglo XX es el que realiza Leopoldo Torres Balbás (1888-1960) en su ensayo sobre las nuevas formas de la arquitectura, donde procura ir más allá de la ramplona constatación de la crisis para apuntar una salida viable, buscando cuáles han de ser los motores de esa nueva arquitectura sin sustento en los prestigiosos estilos del pasado.

Cifra las esperanzas de futuro en dos cuestiones que a su juicio dan la clave de la evolución del proceso creador en la construcción. Por una parte:

La idea del progreso humano en marcha continua, capaz de ir dominando el tiempo y el espacio. Sus creaciones, clasificadas hoy como de la ingeniería en una división que comienza a ser algo arbitraria, son las más bellas de nuestra civilización (Torres Balbás, 1919: 147).

El otro ideal sería el de:

la redención de los parias, de los miserables, el derecho de todo ser humano á alcanzar una vida en la que, libre de la miseria y de la injusticia, pueda disfrutar de los goces y tormentos de la inteligencia y del arte (Torres Balbás, 1919: 147).

Ideal de difícil concreción estética, pero que refleja tanto el convencimiento de que este camino estaba ya abierto para la arquitectura y para la sociedad, como la preocupación de los intelectuales de la época por los avatares del pueblo ruso tras la revolución de 1917 (Isac, 1987: 352-353). Estaríamos ante el comienzo de una nueva era, que viene definida por la agonía de:

Formas tradicionales de una arquitectura basada fundamentalmente en principios estáticos, surgen esas otras formas de una belleza tan moderna y tan grande, de la arquitectura del movimiento, propia de los tiempos presentes. El pasado son la piedra y la madera, materiales con los que ya no tenemos nada que decir; el porvenir está en el hierro, el cobre y el acero (Torres Balbás, 1919: 148).

Este ideal de arquitectura, que por su descripción es plenamente equiparable con el que recogen los diversos manifiestos que definen la estética del Futurismo, la identifica con la arquitectura propiamente moderna y, como tal, representativa de nuestra época, a la vez que manifiesta el rechazo contra los historicismos. 
Y es que la arquitectura clásica, la que levanta los edificios de nuestras ciudades, es un arte viejo y en plena decadencia. Es inútil querer resucitarle. Otras formas bellísimas que contemplamos diariamente, constituyen la verdadera arquitectura de la hora actual y tienen la sugestiva modernidad que anhelan nuestros espíritus.

Son las que pudiéramos llamar de la arquitectura dinámica: los grandes trasatlánticos de curvas graciosas y enérgicas, los acorazados formidables, las locomotoras gigantescas que parecen deslizarse por las praderías, los aeroplanos que imitan como casi todas las anteriores las formas de la naturaleza.

Ellas, unidas á las de los viaductos y puentes metálicos, las modernísimas estaciones de ferrocarril y las enormes fábricas construidas durante la guerra, hacen que nuestra época pueda compararse arquitectónicamente a la de los templos griegos y las catedrales góticas (Torres Balbás, 1919: 148).

En febrero de 1920 la revista Arquitectura lanzaba a la calle un monográfico sobre el Barroco. El constructor del entramado ideológico de la monografía fue José Ortega y Gasset (1883-1955), cuyo artículo "La voluntad del Barroco" encabezaba la publicación y hacía de marco al resto de las colaboraciones, encaminadas a la reivindicación del arte barroco a través de la profundización en el estudio de las manifestaciones arquitectónicas de este estilo en nuestro país.

Aquella reivindicación del barroco se lleva a cabo en el contexto de los cambios estéticos acaecidos en Europa, incorporándonos con naturalidad y sin complejos a la mutación que en ideas y sentimientos experimenta la conciencia europea (Ortega y Gasset, 1920: 33) Aunque se trate de una revista especializada en arquitectura, el artículo pretende analizar el nuevo rumbo que toman nuestros gustos estéticos (Ortega y Gasset, 1920: 33) en su globalidad.

Ortega y Gasset parte de la relectura de los autores barrocos, para definir las características de una nueva estética en la que resulta primordial el rechazo de lo determinista e inerte en beneficio de lo semoviente. Aborda los cambios de la crítica artística y literaria respecto a ciertos autores del barroco, después de haber superado una época de rechazo visceral.

Si Torres Balbás aseguraba que las formas de la nueva construcción eran las de la arquitectura del movimiento, la arquitectura dinámica, en una clara 
adopción de los postulados futuristas, Ortega pretende encontrar las raíces hispanas de la nueva estética constructiva en la paleta de Doménico Theotocópuli.

Aquí encontramos también la materia tratada como pretexto para que un movimiento se dispare. Cada figura es prisionera de una intención dinámica; el cuerpo se retuerce, ondea y vibra de la manera que un junco acometido del vendaval. No hay un milímetro de corporeidad que no entre en convulsión. No solo las manos hacen gestos; el organismo entero es un gesto absoluto. En Velázquez nadie se mueve; si algo puede tomarse por un gesto es siempre un gesto detenido, congelado, una "pose". (...) Para el Greco todo se convierte en gesto, en dynamis (Ortega y Gasset, 1920: 35).

Como colofón sitúa al Greco como sucesor natural de Miguel Ángel en la cima del arte dinámico, describiéndolos como provocadores de espanto y desasosiego.

El giro es inmejorable; en esto consiste lo que hoy, y por lo pronto, nos interesa más del arte barroco. La nueva sensibilidad aspira á un arte y á una vida que contengan un maravilloso gesto de moverse (Ortega y Gasset, 1920: 35).

Una vez sentadas las bases conceptuales del entronque del retorno al barroco con la nueva corriente estética europea, el resto de los articulistas abordan la argumentación de la riqueza de la arquitectura barroca española, el por qué merece que se le esté prestando atención desde la nueva arquitectura, destacando que si hasta ahora solamente se habían visto sus defectos; ahora comienzan á verse sus bellezas (Ortega y Gasset, 1920: 46).

Leopoldo Torres Balbás publica dos artículos en este número de la revista, pretendiendo hacer un esfuerzo más valorativo que descriptivo quiere subrayar el arraigo del barroco en nuestro país desde el punto de vista cuantitativo en cuanto a la fecundidad en el número de edificaciones levantadas en el periodo que va desde la segunda mitad del siglo XVII hasta finales del XVIII, como fruto de las riquezas traídas de América, la acumulación de bienes de las órdenes religiosas, y la influencia de los jesuitas. La conclusión tajante a la que llega Torres Balbás es que el barroco era el estilo omnipresente en España, con gran diferencia respecto al resto de los estilos artísticos:

Ciudades como Madrid deben su actual fisonomía al período barroco; Sevilla es en gran parte una ciudad barroca; del siglo XVIII es todo el caserío gaditano; pa- 
lacios, casas consistoriales é iglesias de aquel estilo, dan su especial fisonomía á las villas vascongadas; en Santiago de Compostela y en toda Galicia, el arte barroco levantó edificios enormes, de los más monumentales de España; en Valencia el barroco da carácter á gran parte de la ciudad, y aun en la dorada Salamanca parece que el arte barroco quiere competir con el renacimiento con obras tan hermosas como la Clerecía y la Plaza Mayor. No hay pueblo ni aldea perdida en nuestras sierras que no tenga por lo menos un dorado altar barroco, cuyas columnas, envueltas en racimos y hojas de vid, se retuercen sosteniendo la vertiginosa profusión de entablamentos que horrorizaban por sus licencias á los neoclásicos (Ortega y Gasset, 1920:47).

Se atreverá, además, a hacer una aproximación a la sociología del español, opinando que el barroco con su arquitectura «ostentosa y petulante», es el estilo que mejor se identifica con la imagen del español como el hidalgo pobre y altivo que oculta su penuria con un estoicismo y un ingenio insuperables.

\section{España Republicana y Herreriana.}

Pero como el efecto de la piedra caída en el estanque, el anillo externo engloba otro anillo interno. De la clara reivindicación del estilo barroco llevada a cabo en 1920, como la versión española del espíritu del futurismo europeo, que se lleva a cabo desde las páginas de Arquitectura, se pasará, tres años más tarde, a la reivindicación del monasterio de San Lorenzo de El Escorial como el edificio paradigmático de la arquitectura moderna española.

A primera vista, defender el Escorial como representación modélica del estilo barroco puede parecer una deformación estética, en la medida en que los entomólogos de la historia del arte nos habían acostumbrado a tener que abrir el cajón del Renacimiento cada vez que queríamos acudir al Monasterio.

Hemos de constatar que no todos los expertos en historia de la arquitectura pensaban así, ni Leopoldo Torres Balbás ni Ortega y Gasset. Parece razonable plantearse la dificultad de contener bajo el epígrafe de "Arte del Renacimiento" la mole del Monasterio por la incomodidad generada por su escaso parecido con los referentes canónicos del Renacimiento, su manifiesto desfase cronológico y formal respecto al arte italiano del Quatroccento y -principalmente- por ser tarea de Titanes meter en el corsé del equilibrio, la mesura y la armonía, un 
edificio tan teatral, extremo, exagerado y peculiar como aquél. Así lo expresaba Luis Moya Blanco:

Toda la fachada es una soberbia escena teatral para el acto de la Parada, porque casi todo es falso en su aspecto funcional y estructural, aunque verdadero como efecto visual bien planeado.

Las portadas laterales, para empezar, no conducen a ningún gran acceso recto, sino a pequeños vestíbulos con salidas laterales. La portada central es una fachada de iglesia del Renacimiento italiano aplicada, como un repostero, sobre un edificio de varias plantas. (...)

Nada en lo exterior indica la existencia de la Biblioteca, y nada dentro de la Biblioteca indica la existencia de la portada, cuyo entablamento dórico -enorme mole de piedra alta como un piso normal-cruza a mitad de altura del gran salón.

Encuadran la fachada dos torres, también piezas escenográficas, pues no son cuadradas, como aparentan desde la Lonja. Tienen en realidad planta de escuadra, porque los claustros pequeños, adyacentes a ellas, entran en el cuadrado que les correspondería. (...)

Más elaborada aún es la presentación de la fachada Sur. (...)

También esta fachada es en parte, aunque menos que la principal, bastante escenográfica. Nada en ella indica la existencia de grandes salas de doble altura (Salas Capitulares, etc.), pues todos los huecos son iguales a los que corresponden a las celdas de los frailes, que son el módulo.

El jardín no es, ahora, el que hizo Felipe II. Aquél no tenía dibujos geométricos hechos con boj recortado, sino cuadros de flores procedentes de todo el Imperio. En vez de la monocromía actual era una explosión de colores y formas. Eran los trópicos con todo el veneno oculto de su barroco, que había ya notado Eugenio d'Ors al relacionar el Barroco por antonomasia con los grandes descubrimientos (Moya Blanco, 1963: 155-180).

La primera investigación del siglo XX sobre la arquitectura barroca en España también lo afirmaba. Otto Schubert (1878-1968) doctor arquitecto (1906) y catedrático de la Universidad Politécnica de Dresde, vino a España en 1903 y 1905 para documentarse con material fotográfico, dibujar plantas, secciones y alzados de los edificios más representativos, y realizar un amplio estudio positivista acerca del periodo barroco, basándose en una extensa bibliografía reco- 
gida in situ. Con ese material redactó su trabajo Geschichte des Barock in Spanien, publicado en 1908 y traducido al castellano en 1924. Para el Marqués de Lozoya, Schubert había sido nada menos que el descubridor del barroco español (Stiglmayr, 1995: 107)

Para el estudioso alemán, el Monasterio de El Escorial era el punto de partida de la arquitectura barroca en España, según sus propias palabras: “Tal como es la obra terminada, se alza como piedra angular entre la decoración del Cinqueccento introducida de Italia y el arte individual que crea con conciencia de su fuerza, sobre la base de los fundamentos clásicos: con ella se inaugura el Barroco en el arte español"1 (Schubert, 1924: 37-38).

Luis Lacasa Navarro (1899-1966) fue el primer arquitecto español en hacerse eco de la trascendencia del libro de Otto Schubert, durante su estancia en la ciudad alemana de Dresde, en la que el citado autor era una autoridad reconocida en la materia, pudiendo conocer la obra del arquitecto alemán antes de haber sido traducida al castellano (Scholz-Hänsel, 1995: 119-120), lo que le permitió -dado el interés del libro para los estudiosos españoles- que la revista Arquitectura le publicara una larga reseña del trabajo del investigador alemán, iniciativa con la que se sumará a la corriente de recuperación del barroco (Lacasa, 1923: 72-75).

El entusiasmo de Lacasa ante el descubrimiento en Dresde del estudio sobre la arquitectura barroca española no hizo más que refrendar la coherencia de su actitud de rechazo tanto del esteticismo del racionalismo de Le Corbusier, como del historicismo de copia fragmentaria, reivindicando la necesidad de fundamentar la nueva arquitectura española sobre las raíces del legado de la tradición. Para Lacasa el estilo barroco sería tan genuinamente nuestro que bien podríamos llamar arte nacional² (Diéguez Patao, 1997:187).

\footnotetext{
${ }^{1}$ Queremos destacar que la cursiva es de origen, no nuestra.

2 Vid. también sobre Lacasa y Schubert: Joaquín Medina Warmburg: “Irredentos y conversos. Presencias e influencias alemanas: de la neutralidad a la postguerra española (1914-1943)", en VV.AA., Modelos alemanes e italianos para España en los años de la postguerra, Universidad de Navarra, Pamplona, 2004, págs. 21-38.
} 
En los artículos que Arquitectura le publica a Ortega y Gasset en el monográfico sobre El Escorial de 19233, apreciaremos el esfuerzo por trascender la masa granítica de sus muros y extraer la esencia filosófica que defina al español, esa era su ambición intelectual, su peculiar sistema de pensamiento basado en el "intento de fundar la filosofía en la vida humana y en la cultura nacional", esfuerzo que en el filósofo madrileño va parejo al de definir una estética española, o una manera española de ver las cosas ${ }^{4}$.

En palabras de Ortega, hosco y silencioso aguarda el paisaje de granito, con su gran piedra lírica en medio, una generación digna de arrancarle la chispa espiritual. Este ejercicio de extrapolación desde el edificio hacia la definición de los rasgos esenciales del carácter español, es algo muy querido por la crítica alemana, poniendo de manifiesto la formación intelectual germanófila de Ortega ${ }^{5}$. Se servirá del paisaje y de la metáfora literaria tomada del Quijote, para hablarnos de la evolución del espíritu europeo, y del de los españoles en particular.

La conclusión orteguiana peca un tanto de pesimista, ya que su visión del esfuerzo renovador de la sociedad de su época, es la de un esfuerzo sin sentido, un esfuerzo entusiasta pero inútil, como el de don Quijote, como el del Monasterio, porque don Quijote será, como Don Juan, un héroe poco inteligente: posee ideas sencillas, tranquilas, retóricas, que casi no son ideas, que más bien son párrafos ${ }^{6}$.

\footnotetext{
${ }^{3}$ Este artículo de (1923) "El Monasterio", Arquitectura, no 50, Sociedad Central de Arquitectos, Madrid, junio, pp. 161-167, aparece recopilado en el tomo VI de El Espectador (1927). Una primera versión se publicó el 29 de abril de 1913, en La Prensa de Buenos Aires, artículo que, retocado, le sirvió a Ortega para una conferencia en el Ateneo, publicada en España (19.IV.1915), como recoge E. Inman Fox en su edición a Meditaciones sobre la literatura y el arte, Castalia, Madrid, 1988, p. 351. ${ }^{4}$ Inman Fox, E. (1988): “Introducción biográfica y crítica”. En Ortega y Gasset, J., Meditaciones sobre la literatura y el arte, Castalia, Madrid, págs. 7-9.

${ }^{5}$ Respecto a la vinculación del paisaje, la arquitectura y el carácter del individuo como ejercicio de crítica artística por parte de los historiadores del arte alemanes, vid. el ya citado artículo de Scholz-Hänsel, M. (1995): “El historiador del arte como mediador en el discurso intercultural: la recepción de El Escorial en Alemania y su influencia en el debate español", C.S.I.C., Historiografía del arte español en los siglos XIX y XX, Alpuerto, Madrid, págs. 111-122.

${ }^{6}$ Ortega y Gasset, José (1923): "El Monasterio", Arquitectura, no 50, Sociedad Central de Arquitectos, Madrid, págs. 161-167.
} 
La fijación del Escorial como paradigma arquitectónico viene de la mano de Leopoldo Torres Balbás, que en su artículo Lo que representa el Escorial en nuestra historia arquitectónica (Torres Balbás, 1923: 215-219), al ir estratégicamente situado al final de la publicación, recoge como un cauce de río la escorrentía de todos los artículos afluentes que respaldarán sus afirmaciones, que han de ser leídas no como alabanza de la época en la que se levantó su fábrica, sino con plena proyección actual y de futuro de la arquitectura española, de ahí que presente el edificio escurialense como el modelo donde inspirarse, el precedente patrio del arte europeo, siendo:

El primer edificio cronológicamente de la edad moderna en España. Fue un intento de europeización, de implantación del espíritu moderno de occidente en un pueblo tan complejo como el peninsular. (...) En nuestro monasterio el genio español ha puesto su exageración, su extremismo, su falta de sereno equilibrio, es decir, su anticlasicismo (Torres Balbás, 1923:219).

Quien acogió el reto de llevar a la práctica este concepto vanguardista del arte español, de defensa y exaltación del arte barroco en general y del Monasterio del Escorial en particular, como cristalización de una modernidad netamente española fue Secundino Zuazo Ugalde (1887-1970) en su proyecto para los Nuevos Ministerios de La Castellana, en el solar que ocupaba el hipódromo.

El proyecto inicial de los Nuevos Ministerios (...) Zuazo lo comparaba con lo existente en el Monasterio de San Lorenzo de El Escorial: "... ya desde entonces me orientaban e influían en mí las líneas de las lonjas que se crearon en 1563 y que Juan Bautista de Toledo dibujara en su traza universal para el Monasterio de San Lorenzo de El Escorial. Lonjas sobrias, ponderadas calles, ayudando a las arquitecturas. Así serían las que yo proyectase para esta obra trascendental. Sólo obra de arquitectura, tierra desnuda y pavimentos pétreos, sin jardines, sin árboles..., plazas sin tráfico alguno, tranquilas y para el ciudadano, el peatón, y no perturbadas por el tráfico de las grandes arterias; un remanso, sin un coche, ni para estacionar, sólo reservada a actos muy señalados. La gran plaza como una lonja nunca sería estacionamiento de coches y sí como una réplica de las de Felipe II en El Escorial" (Maure Rubio, 1987: 308-310).

Secundino Zuazo Ugalde ya había realizado su particular homenaje al Barroco en 1926 en el Palacio de la Música en pleno Madrid moderno y en el edificio de Correos en Bilbao asocia el neobarroco con el neoplasticismo 
holandés. En 1934 construye el edificio para el Banco de España en Córdoba donde aúna la calidad de la construcción y los materiales, con una exquisita sobriedad decorativa, articulando la fachada mediante tres pilastras corintias de orden gigante y un sencillo cornisamento, dejando las referencias locales para el interior (Zuazo, 1935). Sucumbe también al magisterio de Ortega y Gasset, al que admira y respeta además de compartir las querencias germanófilas, como manifiesta el trasiego continuo de arquitectos alemanes y austriacos por su estudio (Sambricio, 2003: 64-65 y 166 de la Autobiografía).

Zuazo se había convertido en el arquitecto referencia de prestigio reconocido ya desde las aulas de la Escuela de Arquitectura de Madrid, de modo que sus primeros pasos profesionales merecieron la atención de uno de sus maestros, Leopoldo Torres Balbás, que publica un encendido elogio del hotelito que Zuazo realiza en El Escorial en 1917: Espíritu moderno, concisión y sobriedad. Sano regionalismo que no contempla la copia, sino que estudia y crea una obra original, con un sugestivo acento de la remota fuente (Torres Balbás, 1920: 78), que exterioriza el equilibrio, sentido de la proporción y buena interpretación de las lecciones asimiladas en sus años de aprendizaje en la Escuela. Un prestigio que se verá avalado con el paso del tiempo por la calidad reconocida de su trabajo profesional, su capacidad para trabajar en equipo, y la visión de conjunto que fue capaz de desplegar en su labor de urbanista en la Oficina Técnica del Ayuntamiento de Madrid.

Dos hechos trascendentales para comprender el compromiso de Secundino Zuazo con la renovación de la arquitectura española, son su visita a la Exposición de París de 1925, donde impera el Art Déco en el que los arquitectos franceses basaban sus esperanzas hegemónicas de implantación de un gusto arquitectónico moderno, buscando en un clasicismo inspirado en la tradición francesa. El otro hecho trascendental fue el viaje realizado también en 1925 a Holanda, donde lo que más le impactó fue la obra de Willem Marinus Dudok (1884-1974) y la de Hendrik Petrus Berlage (1856-1934), especialmente en la sede de la Bolsa de Amsterdam (1897-1904), un edificio inspirado sin rubor en la tradición del románico y el gótico flamencos, pero en el que se evitaba en todo momento el recurso a la copia fragmentaria y servil, como se manifiesta en la radical funcionalidad con la que fue concebido el edificio, al mismo tiempo que se hacía un uso explícito del hierro junto con materiales tradicionales. 
Secundino Zuazo fue, pues, uno de los primeros arquitectos españoles que se dieron cuenta de la importancia del movimiento de renovación arquitectónica que se produce en la Europa central -principalmente en Alemania, Austria y Holandaaños antes de la Gran Guerra y que sigue bajo distintas variantes hasta nuestros días. (...)

Porque Zuazo, que ha sido gran importador de nuevos conceptos (...), no ha dejado nunca de ser tradicionalista a su modo, y en todos sus trabajos, aun en los de mayor actualidad, se advierten brotes poderosos de ese su sentido de la tradición... como en las obras de los grandes arquitectos de nuestro tiempo (Encina, 1933: IX).

Ansias de renovación, entusiasmo por su profesión de arquitecto, inconformismo frente a la mediocridad de la repetición de los estereotipos académicos, claridad de ideas, serenidad y mesura en la expresión de las mismas, le auparon al pedestal clásico del in medio virtus en unos años propensos a las radicalidades en todos los órdenes. Así se gana la admiración de los mejores, como Fernando García Mercadal (1896-1985), que elige trabajar en el estudio de Secundino Zuazo en 1928, el año de su participación en el I CIAM para madurar en su labor profesional.

Los estudiantes le admirábamos más que a ningún otro. Zuazo, que no era profesor de la Escuela, nos abrió nuevos caminos. El fue quien nos hizo comprender a Villanueva (Fernando García Mercadal, cit. por Diéguez Patao, 1997: 134).

En términos parecidos se expresaba Luis Moya Blanco (1904-1990), que se aferró al trabajo de Zuazo como la mejor referencia para unos años en los que surgía con fuerza un novedoso y atractivo racionalismo -que conocía de primera mano como suscriptor de la revista del GATEPAC-, mientras que su sensibilidad se iba consolidando en una arquitectura basada en un clasicismo de tradición española (Capitel, 1982). Según sus propias palabras:

La 'ideología' que puede encontrarse en mi obra es la que implantó Indalecio Prieto, como ya he comentado muchas veces, con el edificio de los Nuevos Ministerios en Madrid, concebido por él en 1932 y encargado a Secundino Zuazo con la idea de que fuese para la República lo que el Escorial había sido para la monarquía. Prieto quería que se pareciese al Escorial, pero "en grande", superándolo en tamaño. Así programó el estilo escurialense como el estilo a seguir: él fue el que nos marcó el camino a todos, y a mí, que estaba relacionado profesionalmente, 
aunque de modo indirecto, con la oficina redactora y ejecutora del proyecto (Luis Moya Blanco, cit. por Ochotorena, 1987: 39)

Su prestigio explica sobradamente que sobre él recayera la designación para ser el diseñador del edificio más importante (simbólicamente al menos, para salvar la hipérbole) que se construye en España bajo el Gobierno de la II República. Aunque tenga que luchar contra la obstaculización permanente de la minoría socialista del Ayuntamiento de Madrid, contará en los momentos más difíciles con el respaldo de Indalecio Prieto y del propio Presidente Azaña, que comparten la visión sobre su proyecto de accesos a Madrid y la urbanización de la Castellana.

Teníamos un concepto de España para la cual trabajábamos -que no era ni blanca, ni negra, ni roja- muy distinto del que tenían las gentes, los partidos y los personajes políticos. Éramos quienes recordábamos el pasado, trabajábamos para el presente y para el porvenir (Sambricio, 2003: 218).

Audaz fue la ocurrencia de Indalecio Prieto, una nueva imagen para un nuevo régimen político, una nueva sede centralizada para los órganos de gobierno de la República. Secundino Zuazo conecta inmediatamente con el ministro republicano y presenta su proyecto ante el Gobierno de la República, el Ayuntamiento de Madrid, con su Alcalde a la cabeza, y el Gabinete Técnico de Accesos y Extrarradios, el 28 de diciembre de 1932:

Al final de mis explicaciones hice alusión a lo que significaría la orientación de la arquitectura que pretendía incorporar a los edificios. Les dije que buscaba el entronque moderno con la arquitectura revolucionaria que levantó Felipe II, en el siglo XVI, en el Monasterio de San Lorenzo de El Escorial.

Durante la Guerra Civil vivió en Francia, y al regresar a España se encontrará con que había sido condenado por la coalición vencedora a «Inhabilitación temporal para el desempeño de cargos públicos, directivos y de confianza, y contribución de segundo grado en el ejercicio de la profesión», que en la práctica le supuso el destierro a Las Palmas desde 1940 hasta 1943 por haber acepta-

\footnotetext{
${ }^{7}$ Interesante testimonio de Zuazo de conocimiento y pasión por El Escorial en su discurso de ingreso en la Academia de Bellas Artes (Zuazo, 1948).
} 
do un encargo por designación directa de la República y no por concurso abierto. (Baldellou, 1995: 16-19)

\section{Una 'Nueva Arquitectura' para un 'Nuevo Régimen'.}

Una nueva política necesita una nueva arquitectura, como brazo fuerte de la propaganda de un nuevo orden de una España 'imperial y eterna' que viene a reducir a cenizas la cultura del periodo precedente y a fomentar, retomando como punto de partida la tradición imperial hispana, una nueva edad para las letras y las artes.

Los elementos constitutivos esenciales de la utopía franquista de la "nueva" arquitectura de posguerra son, a nuestro entender: la recomposición de la unidad de España a través de la tradición, "rota" por la vía de la moda extranjerista -el Cubismo y el Movimiento Moderno- y por la de la imitación servil de los historicismos; el retorno a la sencillez de una vida placentera, gravemente dañada por el régimen de corte urbano anterior; conferir mayor importancia a los intereses comunitarios que a los individuales; y espiritualismo -mundo agrícolafrente a materialismo -mundo industrial-. El "cubismo sovietizante", el "ilimitado racionalismo", junto con la industrialización, las oligarquías financieras, el marxismo, la decadencia intelectual, producen los monstruos de hierro, cemento y mármol que convierten las nobles perspectivas de España en campos de alucinación ${ }^{8}$.

En todo ello trasciende la beligerancia dialéctica que tiene como trasunto la imposición de un estado jerárquico dirigido por un líder invicto, frente a su contrario democrático y liberal, como garante de una férrea gestión -transparente y eficaz- frente a un pasado constituido por un anárquico y corrupto capitalismo burgués. Posesión del agua, de la electricidad, de la radio, de los teléfonos, de la gasolina; donde no posesión, dominio 9 .

De ahí que lo que encontraremos en estos momentos de euforia alienadora serán exégesis arquitectónicas que contienen no la resolución de unos problemas técnicos y de organización, que no se pueden acometer, sino diarrea impe-

\footnotetext{
8 Víctor de la Serna (1943), en Llorente Hernández (1995: 70).

${ }^{9}$ Laviada, Samuel (escultor), Moya, Luis (arquitecto), Vizconde de Uzqueta (militar) (1940):

"Sueño arquitectónico para una exaltación nacional", Vértice, Madrid. En: Ureña, G. 1979: 292.
} 
rial y verborrea arengadora. Lo que no sabemos es a quién iba dirigida la arenga exegética, si a las masas en las colas de los racionamientos, a los profesionales que no tienen quienes los contraten, o a los depurados en el exilio para que se asusten o se mofen ante tamaño despropósito.

La piedra es la tradición de "Roma" en la arquitectura española. La piedra de los acueductos y puentes cesáreos. La piedra que informó los primeros castillos asturianos y roqueros de la Reconquista. La piedra (...) que sirvió para construir las catedrales de León, Burgos, Valladolid, Ávila. Y los palacios de Toledo. $Y$ los sillares de El Escorial. La piedra, en la arquitectura española, es el elemento matriz y tradicional: romano.

Junto a la piedra, la pizarra (...). La pizarra es el elemento germánico que la Casa de Austria -ese Felipe II soñador de paisajes con nieblas y bosques- aportó a la tradición románica y humanística de la piedra en España.

(...) El ladrillo. (...) Elemento -el ladrillo-: tierra, barro, marga, polvo, suelo mismo, pueblo mismo e ínfimo de España, en su lucha secular contra la piedra, dominadora y aria. La lucha entre piedra y ladrillo (cristianos e infieles, nacionales y rojos) duró largos siglos medievales sin resolverse en el frente arquitectónico de España, con escaramuzas fronterizas. Hasta que Madrid logró su unificación. Aceptando al "ladrillo en su sitio estricto". Encuadrado y vigilado. Pero utilizado ${ }^{10}$.

Podemos sacar en claro que lo que se pretende es entronizar oficialmente a un arquitecto como guía de todos los constructores: Juan de Herrera, y una obra como luminaria de todas las que se vayan a proyectar: El Escorial. Hasta tal punto se sublimará la imagen del Monasterio como encarnación de un nuevo imperio en periodo de construcción, que en un retrato alegórico y post mortem que encarga Falange a Miguel del Pino para inmortalizar la figura de José Antonio Primo de Rivera, el único fondo que se permite es el de la silueta del Escorial, ya que para ellos era el único lugar digno para depositar el cadáver del líder jerezano hasta su traslado al Valle de los Caídos.

Mole de disciplina y doctrina, teología de piedra, ley armada al sol, en duro y domado granito..., donde se levantaba proféticamente el arca funeral y conmemo-

\footnotetext{
${ }^{10}$ Giménez Caballero, Ernesto (1944), citado por Ureña, G. 1979: 317-319.
} 
rativa del Imperio, y se levantaba también proféticamente, la escena de la Resurrección del Imperio. Piedra de parangón de las Españas, insobornable a todo lo castizo, pintoresco, rancio y banal, insensible a la palabrería tocada al corazón, a las percalinas y luminarias, e impenetrable a lo que no sea universalidad rectora $y$ luminosa de España ${ }^{11}$.

Escorial será también el nombre que lleve la denominada revista culta de Falange, que tras la desaparición de la beligerante Jerarquía, y dirigida por Ridruejo y Laín Entralgo, quiso ser el vehículo de creación del pensamiento sustentador de aquella ideología totalizante y totalizadora. Es decir, poco más o menos, pretendía la cuadratura del círculo.

No se supo crear -si es que se quiso hacer- un pensamiento político fundado en una filosofía. En la medida en que la especulación dependía de las orientaciones oficiales, variaba a tenor de la tendencia personal del ministro de Educación o del presidente del Consejo Superior de Investigaciones Científicas o de la Secretaría de Prensa y Propaganda (Andrés-Gallego, 1992: 36).

El Monasterio será el modelo que se ofrezca desde el poder a los arquitectos. Ya que la política del nuevo régimen se va a identificar con aquella construcción -filipina e imperial-, si se quiere sintonizar arquitectónicamente con la nueva ideología se advierte que el rasero con que se medirá a los arquitectos será el del Escorial.

Como ya había escrito en 1935 Giménez Caballero, "era un Estado. Era el resultado de un arte: el arte de lograr un Estado". Y era el estilo de España-Maravall, llegó incluso a escribir que el estilo de Europa era el estilo de El Escorial-, la "Carta Magna constitucional española en piedra viva" (Sánchez Mazas), "alma nacional de España", "pura razón de Estado y razón de Dios" (Montes) (Llorente Hernández, 1995: 80).

Por tanto el arquitecto oficial del régimen -al menos para los falangistas-, no podía ser otro que Juan de Herrera. $\mathrm{O}$ al menos ese era el nombre que le daban a una personalidad demiúrgica, oráculo de la interpretación de la política de un imperio a través de su imagen arquitectónica -erigió su convicción

\footnotetext{
11 Sánchez Mazas, Rafael (1939), citado por Ureña, G., 1979: 163 y ss.
} 
viril, totalitaria y armoniosa en claro magisterio universal-, que poco tenía que ver con un simple mortal, por muy arquitecto de Felipe II que fuese. A Juan de Herrera, en un claro abuso de la retórica evocadora, no se le considera solamente constructor -en su triple conciencia matemática, física y metafísica-, sino, sobre todo, hombre integro, hombre de una pieza, varón imperial de gran peso y altísimo vuelo (Sánchez Mazas, 1939: 263).

Herrera conocía hasta el fondo el "ubi consistat" de la arquitectura (...) Lleno de un alto menosprecio por todo lo típico y castizo -que abigarraba el plateresco-, tuvo ocasión de levantar su mole para una dinastía cuya sangre venía de Alemania. (...) Hizo tabla rasa, hasta en el paisaje, de todo tradicionalismo pintoresco, sensiblero, decorativo y menor; de todo énfasis localista -por muy hidalgo montañés que él fuera- y partió para su concepción magistral e imperial de las grandes ideas universales y de su función y representación propias, que plásticamente se logran, sobre todo, por la simple y seria conciencia de los cinco poliedros regulares (Sánchez Mazas, 1939: 264-265)

El único tratado sobre la nueva arquitectura con aspiraciones de rigor y exhaustividad fue el "Ensayo sobre las directrices arquitectónicas de un estilo imperial" de Diego de Reina de la Muela, donde dicho autor:

Formula el único intento serio y coherente de "recetario" práctico de lo que debía ser una arquitectura imperial y española, planteando una identificación entre Arquitectura, Estado e Imperio mediante la obtención de diez elementos formales: unidad, universalidad, actualidad, serenidad, austeridad, dignidad, perennidad, verdad, simetría y escala. El resultado será plantear una serie de indicaciones concretas sobre el arte arquitectónico en lo referido a los conjuntos, las masas, alzados, plantas, estructuras, materiales, los órdenes, los huecos, balaustrada..., de lo que se aprecia que su obra pretende ser exhaustiva y consigue más que ninguno la formulación del estilo arquitectónico de ese Nuevo Orden del estado franquista (Ruíz García, 1993: 87)

Un paso más en esta simbiosis fue el papel otorgado a Madrid como "Capital Imperial" y "Ciudad del Movimiento". A semejanza de Felipe II, que gobierna el Imperio desde El Escorial, centralizándolo todo en una persona y en una ciudad, Franco dirige los designios de España desde Madrid, que pasa a ser la capital del Nuevo Imperio, en sustitución de Burgos. Por tanto, junto a la concentración de poderes en el organigrama férreamente centralista del nuevo Estado, 
y la exaltada demagogia simbolista imperante, Madrid pasa a cargar sobre sus espaldas con las mismas responsabilidades de Estado que el propio Caudillo, ya que será el espejo donde se miren el resto de las ciudades y pueblos de España para encarnar el espíritu del «glorioso resurgir», de la «Ciudad del Movimiento», que tendrá la obligación de reflejar en su fisonomía la alta misión universal y eterna de la España Imperial.

Yo afirmo, con la seguridad que da la fe en nuestro destino histórico y la confianza plena en nuestro Caudillo, que así como Madrid fue ejemplo funesto durante el proceso de decadencia nacional, será también ejemplo vivo y exponente máximo de nuestro resurgimiento y de la construcción del nuevo Imperio ${ }^{12}$.

Por tanto, ¿cuál es el estilo con el que hay que dotar a Madrid? ¿Tiene Madrid un estilo aprovechable, promocionable como el estilo de la "Ciudad del Movimiento"?

Yo creo que no podemos vacilar en la elección de estilo. Miremos el Madrid romano-austríaco del Imperio español. El Madrid de los Ausburgos. Si en la época de la España imperial nuestro pueblo dio de sí su máximo esfuerzo histórico en la urbe, quiere decir que también hubo de darlo, aparte de otras manifestaciones, en arquitectura. Y así fue, efectivamente. En la arquitectura del Madrid ausbúrgico estaba no sólo el "pasado" arquitectónico de España, sino que se preparaba, germinal, todo el "porvenir"13.

La fachada representativa de la Capital Imperial, se piensa que debe situarse en la cornisa que origina el Manzanares y en la que se emplazan algunos de los edificios representativos del Madrid antiguo como el Palacio Real. Del diseño de este conjunto monumental se encargará el arquitecto Pedro Bidagor (19061996), al frente de la Oficina Técnica creada para la ocasión. A pesar de su juventud, este arquitecto había trabajado a principios de los años 30 codo a codo con Secundino Zuazo Ugalde en el Ayuntamiento de Madrid, para dar vida a un plan urbanístico para la capital de España, de concepción plenamente racionalista.

12 Pérez Mínguez, Luis (1940), cit. por Terán, 1982: 122-123.

${ }^{13}$ Giménez Caballero, Ernesto (1944), cit. por Ureña, 1979: 317-319. 
Otro de los centros de atención sobre Madrid es la configuración de las arterias de acceso a la "Ciudad del Movimiento": La Vía Europa, por ser la entrada Noreste; la Vía Imperio, acceso a la Plaza de Atocha (hoy M-30 SUR) conectando con el gran eje Norte-Sur de la Castellana; la Vía Victoria que recoge las rutas del Nor-Oeste (carretera de La Coruña) cruzando a través de la Casa de Campo y enfilando la cornisa del Manzanares.

La arquitectura oficial el Régimen cumplirá su palabra de ir por delante, de modo que para crear la escenografía espectacular que reciba a los visitantes que entren a Madrid por una de estas arterias recicladas de planes anteriores, como era la denominada Vía de la Victoria, se ubicará el nuevo edificio para las dependencias del Ministerio del Aire. Entre los proyectos presentados a concurso, algunos de estética marcadamente fascista, se terminó escogiendo una réplica de El Escorial.

Me parece un error que, a la entrada de la modernísima Ciudad Universitaria -por poner un ejemplo-, se construya un edificio como el Ministerio del Aire, del arquitecto Luis Gutiérrez Soto, escurialense cien por cien; sin que ello quiera decir que no sea una obra bien estudiada y bien construida, que eso nada tiene que ver. (...) No sólo es el enorme edificio en sí, terminado por cuatro grandes torres rematadas por chapiteles poblados de pizarra, es el conjunto que componen con el edificio principal otros en ángulo con los que se cierra la plaza que ante el Ministerio se ha creado, y la urbanización nueva que se ha hecho, componiendo el conjunto con una manzana de construcciones, en curva, que resuelve el encuentro de los ejes de la calle Princesa y el central de la avenida de la Ciudad Universitaria. En esta parte curva, cuya ordenación entona con la del Ministerio, se colocará el Monumento a los Caídos y en la dirección a la Universitaria, se emplaza el gran arco de triunfo, llamado de la Victoria, ante el cual, en una urbanización especial, se colocará la estatua ecuestre del General Franco (Giner de los Ríos, 1952: 103 y ss.)

Lo de haber dado en la diana con la iconografía emblemática del estilo imperial que anhelaba el régimen fue un estigma que persiguió a Luis Gutiérrez Soto (1900-1977) durante el resto de su vida, muy a su pesar. Según se deduce de sus declaraciones quiso dar un paso más allá de lo que hizo su admirado Zuazo en Nuevos Ministerios, pero se equivocó meridianamente tomando un camino equivocado, siendo como fue uno de los pocos arquitectos españoles cuya obra interesaba fuera de nuestras fronteras (vid. S.A. 1934). 
Así, que de este éxito no deseado, sacó nuestro arquitecto como propósito quitarse de encima a la primera oportunidad el título de "arquitecto-talismán" del franquismo. De modo que cuando el General Vigón, henchido de entusiasmo por el buen hacer de su protegido, tuvo a bien encargarle nada más y nada menos que los nuevos edificios para el Estado Mayor en plena Castellana (1949-1953), a Gutiérrez Soto, plenamente consciente de lo que hacía, no se le ocurrió otra cosa que espetarle al general una buena dosis de apestado racionalismo -brise-soleil de Le Corbusier incluido-, lo que le valió la ansiada vitela de arquitecto proscrito para encargos oficiales, ya que el General no le perdonó la decepción que le había provocado al abandonar los criterios tradicionalistas e imperiales.

\section{Bibliografía}

ANDRÉS-GALLEGO, José (1992): "El fondo antropológico de la idea de España". En VV.AA., La época de Franco, Rialp, Madrid, págs. 25-50.

BALDELLOU, Miguel Ángel (1995): "Desarraigo y encuentro. Las arquitecturas del exilio", Arquitectura, no 303, III trimestre, COAM, Madrid, págs. 16-19.

C.S.I.C. (1995): Historiografía del arte español en los siglos XIX y XX. VII Jornadas de Arte, Alpuerto, Madrid.

CAPITEL, Antón (1982): La arquitectura de Luis Moya Blanco, COAM, Madrid.

DiÉGUEZ PATAO, Sofía (1997): La generación del 25: primera arquitectura moderna en Madrid, Cátedra, Madrid.

ENCINA, Juan de la (1933): Arquitectura contemporánea en España. Tomo I. El arquitecto Zuazo Ugalde, Ed. de Arquitectura y Urbanismo, Madrid.

GIMÉnEZ CABALlERO, Ernesto (1944): Madrid nuestro, Ediciones de la Vicesecretaría de Educación Popular, Madrid.

GINER DE LOS Ríos, Bernardo (1952): Cincuenta años de arquitectura española (1900-1950), Editorial Patria, Colección Cultura para todos, México.

INMAN FOX, E. (1988): “Introducción biográfica y crítica". En ORTEGA Y GASSET, J. Meditaciones sobre la literatura y el arte, Castalia, Madrid, pgs. 7-9.

IsAC MARTínez DE CARVAJAL, Ángel (1987): Eclecticismo y pensamiento arquitectónico en España: discursos, revistas, congresos, 1846-1919, Diputación Provincial, Granada.

LACASA, Luis (1923): “Otto Schubert”, Arquitectura, no 47, Sociedad Central de Arquitectos, Madrid, págs. 72-75. 
LAVIADA, Samuel (escultor), MOYA, Luis (arquitecto), VIZCONDE DE UZQUETA (militar) (1940): "Sueño arquitectónico para una exaltación nacional", Vértice, Madrid.

LLORENTE HERNÁNDEZ, Ángel (1995): Arte e ideología en el franquismo (19361951), La Balsa de la Medusa-Visor, Madrid.

Maure Rubio, Lilia (1987): Secundino Zuazo. Arquitecto, COAM, Madrid.

MEDINA WARMBURG, Joaquín (2004): "Irredentos y conversos. Presencias e influencias alemanas: de la neutralidad a la postguerra española (1914-1943)". En VV.AA. Congreso Internacional Modelos alemanes e italianos para España en los años de la postguerra, Universidad de Navarra, Pamplona, pgs. 21-38.

MOYA BLANCO, Luis (1963): "Caracteres peculiares de la composición arquitectónica de El Escorial", El Escorial, Tomo 2, Patrimonio Nacional, Madrid, págs. 155-180.

__ (1993): La arquitectura cortés y otros escritos, COAM, Madrid, págs. 285-302.

OCHOTORENA, Juan Miguel (1987): "Luis Moya Blanco: arquitectura y pensamiento", Nuestro Tiempo, Universidad de Navarra, Pamplona, pág. 39.

ORTEGA Y GASSET, José (1920): "La voluntad del barroco", Arquitectura, no 22, Sociedad Central de Arquitectos, Madrid, págs. 22-25.

_ (1923): "El Monasterio", Arquitectura, no 50, Sociedad Central de Arquitectos, Madrid, págs. 161-167.

(1988): Meditaciones sobre la literatura y el arte, Castalia, Madrid.

PÉRez MíngueZ, Luis (1940): "Madrid, Capital Imperial", Conferencia en la Primera Asamblea Nacional de Arquitectos.

RUÍZ GARCÍA, Alfonso (1993): Arquitectura, vivienda y reconstrucción en la Almería de posguerra (1939-1959), Instituto de Estudios Almerienses, Colegio Oficial de Aparejadores y Arquitectos Técnicos de Almería, Colegio Oficial de Arquitectos de Almería, Almería.

S.A. (1934): "Piscines dans une ile, a Madrid (1932).- Architecte: Luis Gutierrez Soto", L'ARCHITECTE. Recueil mensuel de l'art architectural publié avec le concours de la Société des architectes diplômés par le gouvernement. Éditions Albert Lévy, Nouvelle Série, Paris, pág. 8.

SAMBRICIO, Carlos (2003): “Introducción”. En ZUAZU UGALDE, S. Madrid y sus anhelos urbanísticos. Memorias inéditas de Secundino Zuazo, 1919-1940, Comunidad de Madrid, Nerea, Madrid.

SÁNCHEZ MAZAS, Rafael (1939): "Herrera viviente", Arriba, 2, VII, 1939. 
SCHOLZ-HÄNSEL, M. (1995): “El historiador del arte como mediador en el discurso intercultural: la recepción de El Escorial en Alemania y su influencia en el debate español". En C.S.I.C. Historiografía del arte español en los siglos XIX y XX, Alpuerto, Madrid, págs. 111-122.

SCHUBERT, Otto (1924): Historia del Barroco en España, Saturnino Calleja, Madrid. SERNA, Víctor de la (1943): "La nueva arquitectura española. Un palacio para la Falange", Informaciones, 20, VIII, 1943.

STIGLMAYR, Cristina Mª (1995): “Visiones de la arquitectura española en la historiografía alemana desde Carl Justi hasta Hanno-Walter Kruft". En C.S.I.C. (1995), págs. 101-110.

TERÁN, Fernando de (1982): Planeamiento urbano en la España contemporánea (1900-1980), Alianza, Madrid.

TORRES BALBÁs, Leopoldo (1919): "Ensayos. Las nuevas formas de la Arquitectura", Arquitectura, no 14, Sociedad Central de Arquitectos, Madrid, pág. 145. (1920): "La arquitectura moderna en la Sierra de Guadarrama: la obra de Zuazo en el Escorial", Arquitectura, nº 23, Sociedad Central de Arquitectos, Madrid, pág. 78.

__ (1923): "Lo que representa el Escorial en nuestra historia arquitectónica", Arquitectura, no 50, Sociedad Central de Arquitectos, Madrid, pgs. 215-219.

UREÑA, Gabriel (1979): Arquitectura y urbanística civil y militar en el período de la autarquía (1936-1945): análisis, cronología y textos, Istmo, Madrid, pgs. 317-319.

ZUAZU UGALDE, Secundino (1935): "Memoria del proyecto de nueva planta para sucursal del Banco de España, Av. Gran Capitán, 11, por D. Leopoldo Cano Frades. Arquitecto: Secundino Zuazo Ugalde". Archivo Municipal, Caja 398, Obras Particulares, Madrid.

(1948): Los orígenes arquitectónicos del Real Monasterio de San Lorenzo del Escorial. Discurso leído por el Sr. D. Secundino Zuazo Ugalde en el acto de su recepción pública y contestación del Exmo. Sr. D. César Cort y Botí. El día 8 de noviembre de 1948, Real Academia de Bellas Artes de San Fernando, Madrid.

_- (2003), Madrid y sus anhelos urbanísticos. Memorias inéditas de Secundino Zuazo, 1919-1940, Comunidad de Madrid, Nerea, Madrid. 